\title{
In vitro evaluation for compatibility of additives with Beauveria bassiana (Balsamo) Vuillemin
}

\author{
P. Swathi ${ }^{{ }^{*}}$, P. N. Ganga Visalakshy ${ }^{2}$ and S. B. Das ${ }^{1}$
}

\begin{abstract}
An in vitro evaluation was conducted for compatibility of 12 commonly used additives at three different concentrations of $(0.1,0.5$, and $1.00 \%)$ with Beauveria bassiana through poisoned food technique. The results were expressed as radial growth and growth inhibition of $B$. bassiana on an additive treated medium. All the additives showed an inhibition in mycelial growth of B. bassiana, either partially or completely depending on their concentrations. On overall basis, carboxylmethyl cellulose (CMC) showed the highest radial growth with a least growth inhibition of (77.16 mm and 8.03\%, respectively), followed by Kaolite (69.07 $\mathrm{mm}$ and $17.65 \%$, respectively) and silica gel (65.20 $\mathrm{mm}$ and $22.25 \%$, respectively). These findings concluded that CMC could be used in formulations of B. bassiana with the highest spore load of $4.67 \times 10^{8}$ spore's $\mathrm{ml}^{-1}$.
\end{abstract}

Keywords: Compatibility, Beauveria bassiana, Additives, Radial growth and growth inhibition

\section{Background}

The entomopathogenic fungus, Beauveria bassiana (Balsamo) Vuillemin, has attracted significant interest as a biological control agent since it infects a wide range of insect pests in diverse agro-ecosystems (Ambethgar et al. 2009). B. bassiana is registered biopesticide that act on a broad host range of approximately 700 insect species used for management of several crop insect pests. Entomopathogenic fungi are usually applied in the form of spores, which need a stabilizing agent to facilitate application, stability, and enhancement of activity (Meikle et al. 2008). Bioactivity of $B$. bassiana has been established against several pests at the laboratory level, while efforts are underway to simulate these results in practical scenarios and under field conditions (Mishra et al. 2013). However, successful implementation of entomopathogenic activity shown at laboratory level to field scale necessitates the development of a suitable formulation (Amutha et al. 2010). The present investigation was carried out to study the compatibility of additives with $B$. bassiana under in vitro condition.

\footnotetext{
* Correspondence: padavalaswathi107@gmail.com

'Department of Entomology, JNKW, Jabalpur, India

Full list of author information is available at the end of the article
}

\section{Materials and methods}

The present study was conducted at ICAR-Indian Institute of Horticultural Research, Bengaluru, Karnataka, India. The experiment was carried out using a completely block design of 12 additives at three different concentrations $(0.1,0.5$ and $1.00 \%$ ) (Table 1$)$ in three replicates and a control treatment.

\section{Fungal isolate}

B. bassiana was isolated from mulberry silk worm larvae, Bombyx mori. The fungus was grown on Potato dextrose agar slants and selected based on its virulence against tomato insect pest complex through laboratory bioassay studies with a standard concentration of $1 \times 10^{8}$ spore's $\mathrm{ml}^{-1}$.

\section{Experimental procedure}

Effect of the additives was evaluated on the basis of radial growth and germination of $B$. bassiana. The additives including wetting agents and emulsifiers $\left(\mathrm{T}_{1}\right.$ to $\left.\mathrm{T}_{5}\right)$; humectants' $\left(\mathrm{T}_{6}\right)$; desiccants $\left(\mathrm{T}_{7}\right.$ and $\left.\mathrm{T}_{8}\right)$; crude/refined oils $\left(\mathrm{T}_{9}\right.$ to $\left.\mathrm{T}_{11}\right)$; and detergent carrier $\left(\mathrm{T}_{12}\right)$ along with a control set were evaluated by poisoned food technique in Potato Dextrose Agar (PDA) medium (Moorhouse et al. 1992). Sterilized $20 \mathrm{ml}$ PDA with the additives of 
Table 1 Additives for compatibility studies of B. bassiana

\begin{tabular}{|c|c|c|c|c|}
\hline Tr. Code & Category & Treatments & Importance & References \\
\hline$\overline{T_{1}}$ & \multirow{5}{*}{$\begin{array}{l}\text { Wetting agents } \\
\text { and Emulsifiers }\end{array}$} & Tween-20 & \multirow{5}{*}{$\begin{array}{l}\text { Help to rehydrate spores stored dry and to } \\
\text { disperse clumps }\end{array}$} & \multirow[t]{5}{*}{ Burges (2012) } \\
\hline $\mathrm{T}_{2}$ & & Tween-40 & & \\
\hline $\mathrm{T}_{3}$ & & Tween-60 & & \\
\hline $\mathrm{T}_{4}$ & & Tween-80 & & \\
\hline $\mathrm{T}_{5}$ & & Triton-X & & \\
\hline $\mathrm{T}_{6}$ & Humectants' & Glycerol & $\begin{array}{l}\text { Delays the evaporation of the liquid and favors } \\
\text { spore germination }\end{array}$ & $\begin{array}{l}\text { Kubicek and Druzhinina } \\
\text { (2007) }\end{array}$ \\
\hline $\mathrm{T}_{7}$ & \multirow[t]{2}{*}{ Desiccants } & Kaolite & \multirow{2}{*}{$\begin{array}{l}\text { Regulate water availability to microorganisms } \\
\text { and help in absorption of harmful metabolic } \\
\text { by-products }\end{array}$} & \multirow[t]{2}{*}{ Onions (1971) } \\
\hline $\mathrm{T}_{8}$ & & Silica gel & & \\
\hline $\mathrm{T}_{9}$ & \multirow[t]{3}{*}{ Oils } & Sunflower oil & \multirow{3}{*}{$\begin{array}{l}\text { Improve spore survival and reduce sensitivity } \\
\text { to UV radiations }\end{array}$} & \multirow[t]{3}{*}{ Mishra et al. (2013) } \\
\hline $\mathrm{T}_{10}$ & & Neem oil & & \\
\hline $\mathrm{T}_{11}$ & & Pongamia oil & & \\
\hline $\mathrm{T}_{12}$ & Detergent carrier & $\begin{array}{l}\text { Carboxylmethyl } \\
\text { cellulose (CMC) }\end{array}$ & $\begin{array}{l}\text { Enhances the ability of B. bassiana to reduce } \\
\text { cellulolytic enzymes }\end{array}$ & Petlamul et al. (2017) \\
\hline$T_{13}$ & Control & & & \\
\hline
\end{tabular}

the concentrations $(0.1,0.5$, and $1.0 \%)$ were incorporated into $25-\mathrm{mm}$ diameter sterile petri dishes, and they were allowed to solidify under laminar flow cabinet. An agar disc along with mycelium mat of B. bassiana was cored with the help of cork borer and transferred onto the center of the PDA plate. Growth medium (PDA) without additive, but inoculated with mycelial disc, served as untreated check (control). The plates were sealed with parafilm and incubated at room temperature to allow maximum growth. The diameter of growing culture, i.e., the radial growth in excess of the plugs in each Petri dish, was measured on 10th day after inoculation (DAI). The data were expressed as percentage growth inhibition of $B$. bassiana by additive treated PDA (Hokkanen and Kotiluoto 1992).

$$
X=\frac{Y-Z}{Y} \times 100
$$

where $X, Y$, and $Z$ stand for the percentage of growth inhibition, radial growth of fungus in untreated check, and radial growth of fungus in poisoned medium, respectively.

\section{Results and discussion}

All the additives showed significant differences relating to control in terms of all the observed parameters. Data on growth performance of $B$. bassiana 10DAI in different additives are presented in Table 2 and depicted in Fig. 1.

\section{Radial growth and growth inhibition}

Among the wetting agents and emulsifiers $\left(\mathrm{T}_{1}\right.$ to $\mathrm{T}_{5}$ ) tested, Tween-80@ 0.5\% followed by Tween-80@ 0.1\% showed a maximum radial growth of 51.49 and $50.07 \mathrm{~mm}$ with percentage growth inhibition of 38.58 and $40.30 \%$, respectively.
Among the different concentrations of humectants' $\left(\mathrm{T}_{6}\right)$, Glycerol @ 0.5\%, followed by Glycerol @ $0.1 \%$, presented maximum radial growth of 52.23 and $52.93 \mathrm{~mm}$ and growth inhibition percentage of 37.72 and $36.87 \%$, respectively.

Among the desiccants $\left(\mathrm{T}_{7}\right.$ and $\left.\mathrm{T}_{8}\right)$ tested, Kaolite @ $0.5 \%$, followed by Kaolite @ 0.1\%, showed a maximum radial growth of 73.83 and $66.48 \mathrm{~mm}$ and a growth inhibition percentage of 11.97 and $20.69 \%$, respectively.

Among the tested oils $\left(\mathrm{T}_{9}\right.$ to $\left.\mathrm{T}_{11}\right)$, sunflower oil @ $0.5 \%$, followed by $0.1 \%$, showed maximum radial growth of 55.45 and $45.78 \mathrm{~mm}$ and growth inhibition percentage of 33.98 and $45.42 \%$, respectively.

The data further revealed that among different concentrations of the detergent carrier, i.e., CMC ( $\left.\mathrm{T}_{12}\right)$ @ highest concentration of $1.0 \%$, showed a maximum radial growth of $81.29 \mathrm{~mm}$ and a growth inhibition percentage of $3.13 \%$, respectively.

Thus, among the additives of various categories tested, CMC was relatively less toxic to $B$. bassiana at all the tested concentrations.

\section{Spore load}

Data on sporulation of $B$. bassiana in relation to additives treated media are presented in Table 2 and depicted in Fig. 1.

On the overall basis among the various additives tested at various concentrations, the highest mean spore load was recorded in control $\left(\mathrm{T}_{13}\right)\left(5.22 \times 10^{8}\right.$ spores $\left.\mathrm{ml}^{-1}\right)$ that was at par with $\mathrm{CMC}\left(\mathrm{T}_{12}\right)\left(4.67 \times 10^{8}\right.$ spores $\left.\mathrm{ml}^{-1}\right)$. This was followed by Tween- $80\left(\mathrm{~T}_{4}\right)\left(3.44 \times 10^{8}\right.$ spores $\left.\mathrm{ml}^{-1}\right)$ which was at par with Kaolite $\left(\mathrm{T}_{10}\right)\left(2.89 \times 10^{8}\right.$ spores $\left.\mathrm{ml}^{-1}\right)$ and Glycerol $\left(\mathrm{T}_{5}\right)\left(2.78 \times 10^{8}\right.$ spores $\left.\mathrm{ml}^{-1}\right)$. Meanwhile, the least spore load was recorded in Tween- 


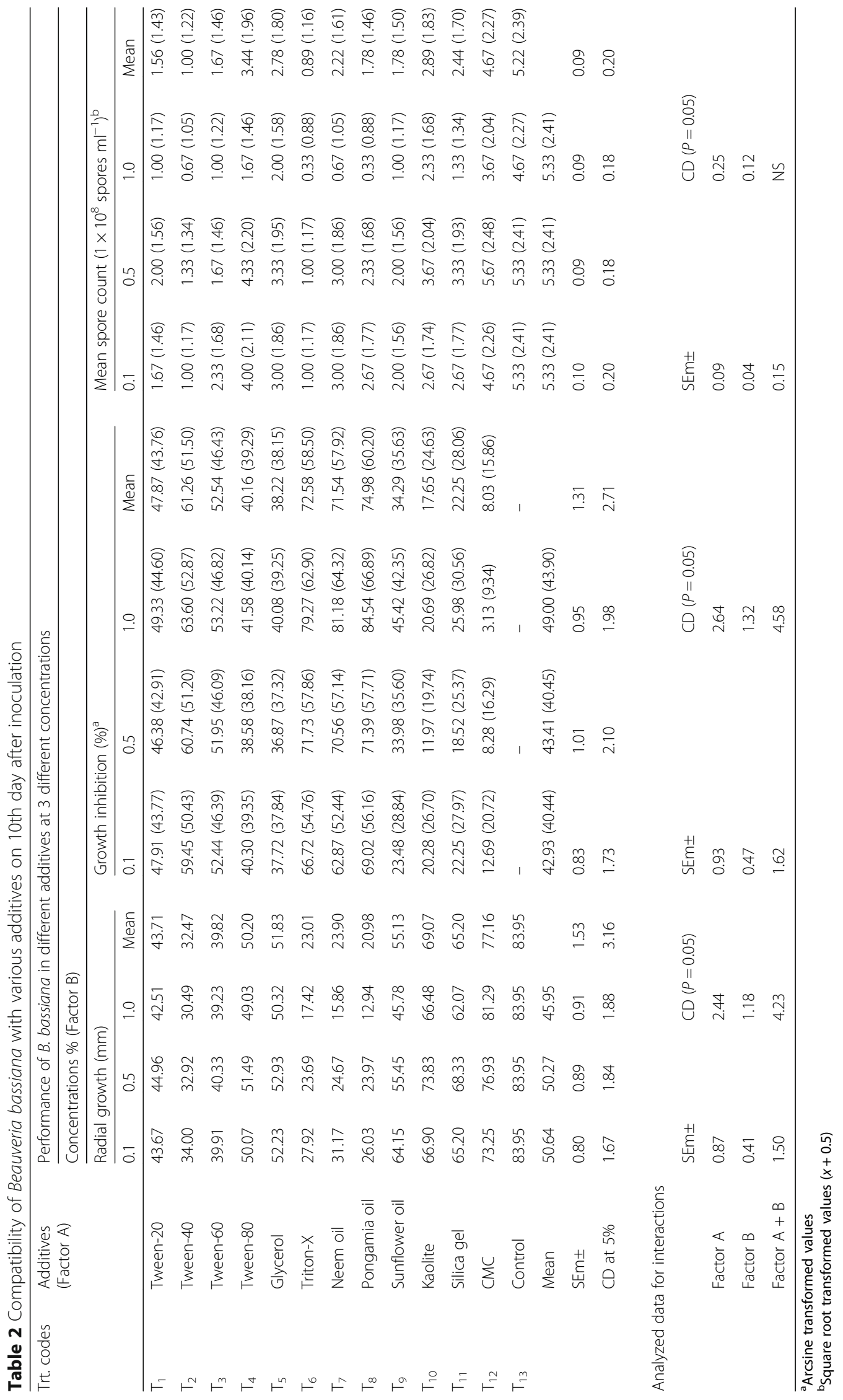




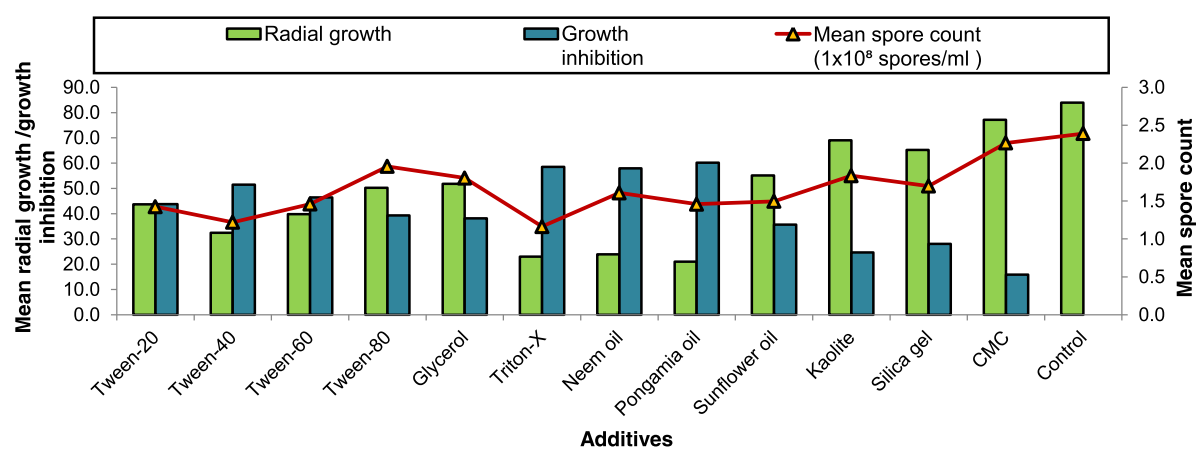

Fig. 1 Mean growth rate (mm), growth inhibition (\%), and spore load of B. bassiana on various additives on the 10th day after inoculation

$40\left(\mathrm{~T}_{2}\right)$ and Triton-X $\left(\mathrm{T}_{6}\right)$ with $1.00 \times 10^{8}$ spores $\mathrm{ml}^{-1}$ and $0.89 \times 10^{8}$ spores $\mathrm{ml}^{-1}$, respectively.

\section{Impact of additives and their tested concentrations on $B$. bassiana}

Perusal of data in Table 2 revealed the following:

a) Radial growth and growth inhibition percentages

Factor A: additives

Different tested additives showed significant impact of the radial growth and growth inhibition percentages on B. bassiana.

Factor B: concentrations

Evaluation of additives at varied concentrations with $B$. bassiana revealed that they had significant impact on the radial growth and growth inhibition percentages of B. bassiana.

Interactions: additives $\times$ concentrations

The interaction effect of additives and concentrations had significant effect on the radial growth and growth inhibition percentages of $B$. bassiana.

b) Spore load

Factor A: additives

Different tested additives showed significant impact on the mean spore load of B. bassiana.

Factor B: concentrations

Evaluation of the additives at varied concentrations of $B$. bassiana revealed that they had significant impact on the mean spore load of $B$. bassiana.

Interactions: additives $\times$ concentrations

Different tested additives and concentrations had nonsignificant interaction effect on the spore load of $B$. bassiana.

In the present study, CMC at all the tested concentrations caused the highest mean radial growth $(77.16 \mathrm{~mm})$ with least inhibition percentage (8.03\%) after control $(83.95 \mathrm{~mm})$; it was found to be relatively less toxic to $B$. bassiana. Results of the growth inhibition of $B$. bassiana in the additives were in accordance with those of Tanuja et al. (2010) who stated that the negative impact of surfactants to microorganism was probably due to increased cell permeability and amino acid leakage through inner membrane. Formulation of myco-insecticide must be compatible with the agent and must enhance its performance and, ideally, must maintain an adequate shelf-life of the agent in order to be successful (Derakhshan et al. 2008).

The highest mean spore load was recorded in $\mathrm{T}_{13}$ $\left(5.22 \times 10^{8}\right.$ spores $\left.\mathrm{ml}^{-1}\right)$ which was at par with $\mathrm{CMC}$ $\left(\mathrm{T}_{12}\right)\left(4.67 \times 10^{8}\right.$ spores $\left.\mathrm{ml}^{-1}\right)$. The present results were in accordance with the findings of Petlamul et al. (2017) who revealed that $B$. bassiana had the ability to release cellulolytic enzymes on CMC for cellulose degradation to carbon source led to their growth.

The assessment of spores compatibility with surfactants is the primary requirement in successful development of surfactant based formulation, viz. emulsion. Particularly, fungi with hydrophobic conidia render the use of surfactants indispensable for laboratory bioassays and field trials (Jin et al. 2008).

Further studies need to be carried out for as a combination in order to achieve additive and develop or increase the efficacy of the fungus.

\section{Conclusion}

The findings conclude that CMC could be used in formulations of $B$. bassiana that helps to enhance its shelf life.

\section{Acknowledgements \\ Authors are thankful to DST for the financial support; Director, ICAR-IIHR, Bengaluru (Karnataka), for providing necessary laboratory facilities; and Department of Entomology, JNKW, Jabalpur, for permitting to carry out the work at IIHR.}

Authors' contributions

All authors read and approved the final manuscript.

Competing interests

The authors declare that they have no competing interests. 


\section{Publisher's Note}

Springer Nature remains neutral with regard to jurisdictional claims in published maps and institutional affiliations.

\section{Author details}

'Department of Entomology, JNKW, Jabalpur, India. ${ }^{2}$ Division of Entomology and Nematology, ICAR-IIHR, Bengaluru, India.

Received: 1 July 2017 Accepted: 6 December 2017

Published online: 15 February 2018

\section{References}

Ambethgar V, Swamiappan M, Rabindra RJ, Rabindran R (2009) Biological compatibility of Beauveria bassiana (Balsamo) Vuillemin isolate with the different insecticides and neem formulations commonly used in rice pest management. J Bio Control 23(1):11-15

Amutha M, Banu JG, Surulivelu T, Gopalakrishnan N (2010) Effect of commonly used insecticides on the growth of white muscardine fungus, Beauveria bassiana under laboratory conditions. J Biopest 3(1):143-146

Burges HD (2012) Formulation of microbial biopesticides. In: Beneficial microorganisms, nematodes and seed treatments. Springer Science \& Business Media, Pub, p 412

Derakhshan A, Rabindra RJ, Ramanujam B (2008) Effect of storage conditions of formulations on viability of Verticillium lecanii (Zimmerman) Viegas and its virulence to Brevicoryne brassicae (L.) J Biosci 8:498-501

Hokkanen HMT, Kotiluoto R (1992) Bioassay of the side effects of pesticides on Beauveria bassiana and Metarhizium anisopliae: standardized sequential testing procedure. IOBC/WPRS Bulletin 11(3):148-151

Jin X, Streett DA, Dunlap CA, Lyn ME (2008) Application of hydrophilic-lipophilic balance (HLB) number to optimize a compatible non-ionic surfactant for dried aerial conidia of Beauveria bassiana. Biol Control 46(2):226-233

Kubicek CP, Druzhinina IS (2007) Environmental and microbial relationships. Springer Science \& Business Media, p 350

Meikle WG, Mercadier G, Holst N, Girod V (2008) Impact of two treatments of a formulation of Beauveria bassiana (Deuteromycota: Hyphomycetes) conidia on Varroa mites (Acari: Varroidae) and on honeybee (Hymenoptera: Apidae) colony health. Exp Appl Acarol 46(1-4):105-117

Mishra S, Kumar P, Malik A (2013) Evaluation of Beauveria bassiana spore compatibility with surfactants. Int Sch Sci Res Innov 7(1):1-12

Moorhouse ER, Gillsepie AT, Sellers EK, Charnley AK (1992) Influence of fungicides and insecticides on the entomogenous fungus, Metarhizium anisopliae, a pathogen of the vine weevil, Tiorhynchus sulcatus. Biocontrol Sci Techn 82(1):404-407

Onions A (1971) Preservation of fungi. In: Booth C (ed) Methods in microbiology. Academic press, pp 156-127

Petlamul W, Sripornngam T, Buakwan N, Buakan S, Mahamad K (2017) The capability of Beauveria bassiana for çellulase enzyme production. Proceedings of 7th International Conference on Bioscience, Biochemistry and Bioinformatics, pp 65-66

Tanuja K, Hemalatha K, Karuna R, Sashidhar RB (2010) Effect of various surfactants (cationic, anionic and non-ionic) on the growth of Aspergillus parasiticus (NRRL 2999) in relation to aflatoxin production. Mycotoxin Res. Springer 26:155-170

\section{Submit your manuscript to a SpringerOpen ${ }^{\circ}$ journal and benefit from:}

- Convenient online submission

- Rigorous peer review

Open access: articles freely available online

- High visibility within the field

Retaining the copyright to your article 